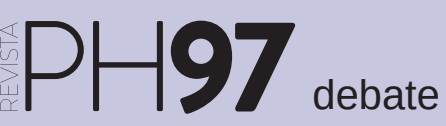

a debate El papel del patrimonio en las nuevas políticas para la cultura, la ciudad y el territorio:

las agendas urbanas como marco de oportunidad

| coordinan Blanca del Espino Hidalgo, Rafael Merinero Rodríguez

\title{
Agendas urbanas territoriales y ODS ¿nuevas políticas para el patrimonio?
}

\author{
María Jesús Sacristán de Miguel | arquitecta \\ URL de la contribución <http://www.iaph.es/revistaph/index.php/revistaph/article/view/4389>
}

Las agendas urbanas derivan de la aplicación de los Objetivos de Desarrollo Sostenible ${ }^{1}$ para las ciudades. Una visión global del patrimonio apoyada en los ODS tiene una apoyatura cultural que permite utilizar herramientas de valoración objetiva como son los indicadores de los ODS. España firmó a finales de 2018 el Convenio sobre el valor social del patrimonio cultural, la declaración de Faro, 2005 Portugal² $^{2}$.

Las leyes pueden distorsionar la efectiva conservación del patrimonio cuando se quedan sólo en papel. El Plan de Acción ${ }^{3}$ para la implementación de la Agenda 2030 desarrolla esta visión transversal de todos los ODS; integra aspectos como los territorios rurales, los paisajes agrarios, los problemas de desigualdad e inclusión, movilidad, cambio climático, acceso a la cultura, servicios esenciales, turismo de masas, diversidad, con el subtítulo de Hacia una Estrategia Española Desarrollo Sostenible.

El valor de estos documentos estratégicos reside en su carácter global y local, por su capacidad de adaptación a los requerimientos locales al seleccionar los objetivos, metas e indicadores que realmente son representativos en el ámbito que trabajemos. Además, el carácter representativo de los ODS reside en la transformación de las tres patas de la sostenibilidad, sociedad, economía y medioambiente, hacia nuevos modelos de gestión que por su flexibilidad aumentan su resiliencia. La fortaleza reside en aprovechar las oportunidades de cada localidad o sector económico en el que lo aplicamos, explorando los parámetros, evaluándolos y valorándolos en el tiempo, lo que facilita la evaluación continuada de las estrategias concretas que hemos aplicado, sea con el plan, programa o agenda urbana redactada. El Plan de Acción español propicia una visión de sostenibilidad que

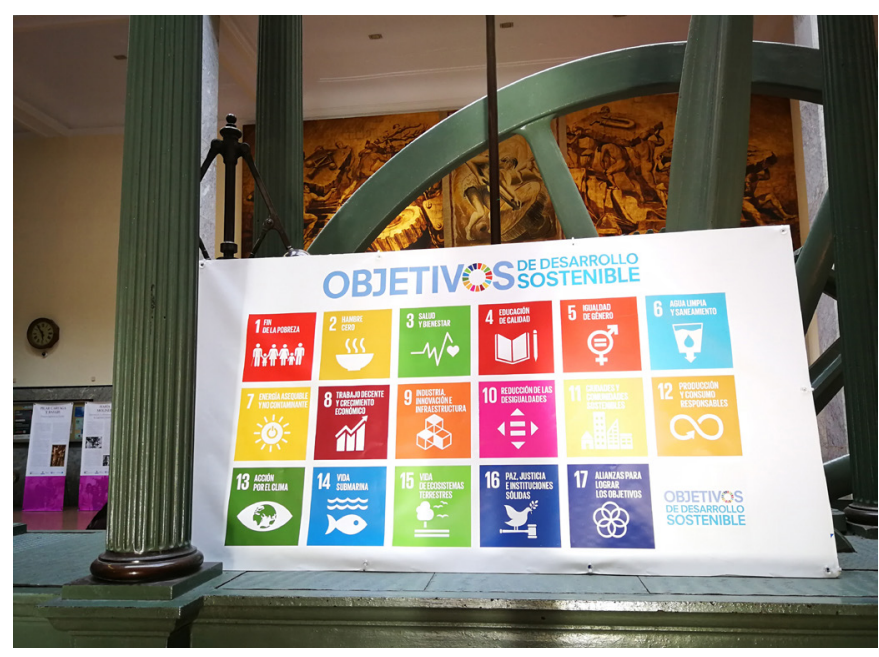

Cartel ODS en la ETSIM de la UPM | foto María Jesús Sacristán de Miguel

valora tanto el territorio natural como la ciudad existente, como un recurso material y energético que se debe reintegrar en el ciclo, considerando la visión de economía circular. Reciclar, reutilizar, rehabilitar, que en el caso concreto de la ciudad, promueve la regeneración urbana en barriadas periféricas, ampliando el concepto de patrimonio más allá de los centros históricos tradicionales.

La transformación en los ámbitos medioambiental y económico exige incorporar en las agendas cómo se va a gestionar la ciudad existente. Desde el siglo XIX se desarrolla el aprecio por los grandes edificios del pasado sobre una consideración de los monumentos como objeto que transmite la memoria de los hechos más trascendentales del pasado de la humanidad, sean técnicas constructivas, pictóricas, escultóricas, arquitectónicas. A lo largo del siglo XX fuimos incorporando al patrimonio otros sectores como ha sido el patrimonio industrial, tanto los edificios fabriles representativos de la Revolución Industrial como áreas urbanas repre- 
a debate El papel del patrimonio en las nuevas políticas para la cultura, la ciudad y el territorio: las agendas urbanas como marco de oportunidad

| coordinan Blanca del Espino Hidalgo, Rafael Merinero Rodríguez

sentativas de estos tejidos dedicados al trabajo. Ahora en el siglo XXI es momento de reivindicar los edificios residenciales, esos que fueron centro de interés para los grandes arquitectos y urbanistas del siglo $\mathrm{XX}$, esos barrios periféricos diseñados con el foco puesto en dar la vivienda más digna y funcional a todos los ciudadanos trabajadores que en las primeras épocas de la Revolución Industrial sufrieron las duras condiciones de hacinamiento, contaminación, infraviviendas y precariedad de infraestructuras habitacionales. Este cambio en el foco de atención del patrimonio lo tenemos que llevar a cabo con las políticas urbanas, y las agendas urbanas, como documentos derivados del Objetivo 11 junto al resto de los ODS, facilitan la implementación de esta visión aperturista; al exigir reducir consumo de recursos y la reutilización, se propicia la reincorporación del patrimonio construido a nuevos usos. Simultáneamente todo el territorio es valorado como un recurso continuo al servicio de todas las especies, vegetales y animales, en toda su biodiversidad, lo que también pone en valor la diversidad urbana como un hecho positivo por aportar mayor resiliencia.

La transformación en el ámbito social exige un compromiso político por parte de todos los ciudadanos, y aquí las actuaciones de las agendas urbanas deben contener aspectos relacionados con la formación y sensibilización en patrimonio. La educación en patrimonio desde las edades más tempranas, incorporar los conocimientos tradicionales sobre tecnologías constructivas locales en la educación reglada. Cambiar los planes de estudio para transformar la sociedad desde la base educativa comienza con los niños, incorporando el aprecio por lo próximo y la curiosidad. En este ámbito destacar los eventos desarrollados por la Universidad Politécnica de Madrid (UPM) ${ }^{4}$ para implantar los ODS en la universidad y difundirlos a la sociedad en general, instituciones y ciudadanos. Los seminarios \#UPM2030 han ido desarrollando en cada jornada una temática específica para explorar en qué medida afecta a la comunidad universitaria, así como al resto de la sociedad, además se debate cómo los investigadores están incorporando estos objetivos en sus investigaciones. Una propuesta muy fruc- tífera para todos los que hemos podido participar en la mayoría de las jornadas, tanto por la oportunidad de profundizar en el conocimiento de estos documentos estratégicos como de idear formas de integrar todas estas teorías en la práctica cotidiana, ya sea a través de las investigaciones, del trabajo formativo cotidiano de los educadores, o en la aplicación práctica en la gestión de los espacios propios de la universidad, o espacios urbanos. Finalmente, apuntar una propuesta de curso abierto a todos, en cualquier lugar en que nos encontremos, en la plataforma online sobre los ODS ${ }^{5}$.

En este sentido se integran las tres vertientes de la sostenibilidad, medioambiental, económico y social, cuando la universidad pueda aplicar sus propuestas en ámbitos urbanos, desde sus propios Campus universitarios a otros barrios de la ciudad, consiguiendo una metodología de implementar estas estrategias en Agendas Urbanas concretas en colaboración con autoridades locales o regionales, y con los ciudadanos en general.

\section{NOTAS}

1. https://www.un.org/sustainabledevelopment/es/development-agenda/

\section{2. https://rm.coe.int/16806a18d3}

3. http://www.exteriores.gob.es/Portal/es/SalaDePrensa/Multimedia/Publicaciones/Documents/PLAN\%20 DE\%20ACCION\%20PARA\%20LA\%20IMPLEMENTACION\%20DE\%20LA\%20AGENDA\%202030.pdf

4. http://www.itd.upm.es/itdupm-en-cifras-2018/

5. http://www.itd.upm.es/cursoods/ 